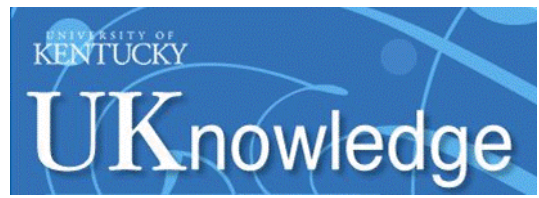

University of Kentucky UKnowledge

2019

\title{
Methods to Quantify Nanomaterial Association with, and Distribution across, the Blood-Brain Barrier in Vivo
}

Robert A. Yokel

University of Kentucky, ryokel@email.uky.edu

Right click to open a feedback form in a new tab to let us know how this document benefits you. Follow this and additional works at: https://uknowledge.uky.edu/ps_facpub

Part of the Pharmacy and Pharmaceutical Sciences Commons 
Methods to Quantify Nanomaterial Association with, and Distribution across, the Blood-Brain Barrier in Vivo

\section{Digital Object Identifier (DOI)}

https://doi.org/10.1007/978-1-4939-8916-4_16

Notes/Citation Information

Published in Nanotoxicity: Methods and Protocols. Q. Zhang, (Ed.).

(c) Springer Science+Business Media, LLC, part of Springer Nature 2019

The copyright holder has granted the permission for posting the book chapter here.

The document available for download is the author's post-peer-review final draft of the book chapter. 
Methods to quantify nanomaterial association with, and distribution across, the bloodbrain barrier in vivo

Robert A. Yokel, Ph.D.

Pharmaceutical Sciences Department

University of Kentucky Academic Medical Center

335 Todd (College of Pharmacy) Building

789 S. Limestone

Lexington, KY 40536-0596

phone: $859-257-4855$

fax: 859-257-7564

e-mail: ryokel@uky.edu

\section{i. Running Head}

Assessment of nanomaterial BBB association and penetration

\section{ii. Summary/Abstract}

The role and functional anatomy of the blood-brain barrier (BBB) is summarized to enable the investigator to appropriately address evaluation of nanomaterial interaction with, and distribution across, it into brain tissue (parenchyma). Transport mechanisms across the BBB are presented, in relation to nanomaterial physicochemical properties. Measures and test substances to assess BBB integrity/disruption/permeation are introduced, along with how they are used to interpret the results obtained with the presented methods. Experimental pitfalls and misinterpretation of results of studies of brain nanomaterial uptake are briefly summarized, that can be avoided with the methods presented in this chapter. Two methods are presented. The in situ brain perfusion technique is used to determine rate and extent of nanomaterial distribution into the brain. The capillary depletion method separates brain parenchymal tissue from the endothelial cells that contribute to the BBB. It is used to verify nanomaterial brain 
tissue entry. These methods are best used together, the latter refining the results obtained with the former. Details of the materials and equipment needed to conduct these methods, and description of the procedures and data interpretation, are provided.

\section{iii. Key Words}

blood-brain barrier, brain parenchyma enrichment, capillary depletion, in situ brain perfusion, in vivo, rat 


\section{Introduction}

To appropriately address nanomaterial interaction with, and distribution across, the blood-brain barrier (BBB) requires an understanding of the BBB's roles and the functional anatomy, physiology, and biochemistry supporting its roles. The BBB has multiple roles. 1) It protects the brain from rapid changes in the level of some substances in the blood that are able to penetrate the BBB and disrupt the brain, such as amino acids. 2) It enables the distribution of some substances from blood to the brain that are needed for brain metabolism, such as glucose and iron. 3) It greatly inhibits the distribution of most pathogens and toxic substances, protecting the brain from their effects while presenting a significant challenge to the intended delivery of therapeutic agents to the brain. The anatomical components of the BBB include the brain microvascular endothelial cells (BMECs) which line the microvessels forming the luminal side of the BBB. They have a near total absence of fenestrations through which substances might diffuse. BMECs differ from endothelial cells that line the vasculature outside of the brain by their inclusion of tight junctions which are formed between adjacent BMECs. When intact the tight junctions prevent passage of ionic substances as small as lanthanum (hydrated ionic diameter $\sim 0.8 \mathrm{~nm}$ ) through this paracellular barrier (1). Proteins maintain the tight junctions, providing indicators for functional BBB alteration, including claudins, occludin, zonula occludens- 1 , junctional adhesion molecules (e.g., ICAM-1), cingulin, annexin A1, VE-cadherin, PECAM-1, and laminens. Microvessels totally perfuse the brain from within this organ (2). They are comprised of 100 billion capillaries, $\sim 400$ miles (600 kilometers) long, with a surface area of $20 \mathrm{~m}^{2}$ in the human, providing a blood vessel within $\sim 10 \mu \mathrm{m}$ of every brain cell (3). They occupy $\sim 2 \%$ of the brain volume in the cortex and a greater space in some other brain regions 
$(4,5)$. A basement membrane surrounds the abluminal side of the BMECs. Within the basement membrane are pericytes that cover $\sim 30 \%$ of the BMEC surface. Astrocyte foot processes extend to cover $>90 \%$ of the abluminal BMEC surface. Neurons interact with this complex of cells to form the neurovascular unit.

The ability of some substances to cross the BBB, whereas others are less or unable to do so, is a function of the physicochemical properties of the substance and the transporters and metabolic processes of the neurovascular unit, primarily in the BMECs. Diffusion of small molecules through the BBB is a product of lipophilicity and the reciprocal of their size $(6,7)$, limiting lipid-mediated diffusion to small molecules that are $<\sim 400 \mathrm{D}_{\mathrm{a}}$ and that form $<8$ hydrogen bonds (8). This rules out nanomaterial distribution across the intact BBB by diffusion, e.g., a $1 \mathrm{~nm}^{3}$ gold particle containing 31 atoms would be $\sim 6100 \mathrm{Da}$. Therefore, diffusion-mediated nanomaterial brain entry requires opening the BBB tight junctions (paracellular transport) or distribution across the BMECs (transcellular transport). The BBB can be intentionally opened by osmotic insult, e.g., $25 \%$ mannitol infusion into a carotid artery, which provides direct delivery of blood to the ipsilateral hemisphere. Focused ultrasound in conjunction with systemically circulating microbubbles has also been used to open the BBB, as the ultrasound causes the microbubbles to expand and contract, putting shear stress on the BBB. Both methods have been used to deliver chemotherapy drugs to treat brain tumors. Conversely, BBB opening can be an adverse effect of nanomaterials that are not intended to be delivered to the brain. 
Although nanomaterials are unable to distribute across the intact BBB by diffusion they have the potential to enter the brain via transcellular, carrier-mediated, transporters. These include nutrient transporters (e.g., GLUT-1 that provides the brain with glucose that the brain cannot generate), metal transporters (e.g., that influx iron), and receptormediated transporters, such as for transferrin and low-density lipoprotein (9). The mechanism of nanomaterial uptake into BMECs is via clathrin-coated pit endocytosis (10).

ATP-binding cassette transporters such as P-glycoprotein and multidrug resistance protein inhibit brain entry by effluxing many structurally-diverse organics, including many drugs. Metabolic processes, including peptidases, CYP 450-linked monooxygenases, and conjugation mechanisms, also inhibit flux across the BBB.

BBB permeability in animals and/or in vitro models can be measured using substances that do not cross the intact barrier. Historically, and currently, this has been done with Evan's blue. Many substances have been used, as shown in Table 1. Small markers might indicate less extensive opening than larger ones. Some, such as sucrose, are paracellular markers; others, such as albumin, are transcellular markers. An additional use of these markers is as vascular volume/extracellular space markers in the in situ brain perfusion technique (below). These markers indicate the vascular and extracellular spaces (volume) of the perfusion fluid containing test substance (nanomaterial), compared to the brain cellular space (test substance uptake into brain parenchyma). 
In vitro BBB models have been extensively studied for decades (11). Their complexity can range from cultured BMECs to co-cultures that include astrocytes, to triple cocultures that include pericytes. As complexity increases the in vivo BBB is more closely modeled. An indicator of BBB integrity, in addition to the use of chemical permeation markers (above), is the trans-epithelial electrical resistance (TEER) across the cells. The TEER of immortalized BMEC monoculture is usually $<50 \mathrm{~m} \Omega \cdot \mathrm{cm}^{2}(12)$ to 200 $\mathrm{m} \Omega \cdot \mathrm{cm}^{2}$ (13). Monocultures of primary BMECS seldom exceed $500 \mathrm{~m} \Omega \cdot \mathrm{cm}^{2}$ (12). A coculture of BMECs with TEER $>600 \mathrm{~m} \Omega \cdot \mathrm{cm}^{2}$ has been described (13). The TEER of arterial and venous vessels in 21 day and older anesthetized rats averaged 1490 and $918 \mathrm{~m} \Omega \cdot \mathrm{cm}^{2}$, respectively, and as great as $5900 \mathrm{~m} \Omega \cdot \mathrm{cm}^{2}(14)$. A monoculture of human-induced pluripotent stem cells differentiated into BMECs had some TEER values exceeding $2000 \mathrm{~m} \Omega \cdot \mathrm{cm}^{2}$, but allowed permeation of $\lg \mathrm{G}$ to a greater extent than seen in mammalian brain (12), suggesting even this in vitro BBB model was not as impermeable as the mammalian BBB.

In addition to the above chemical and electrical indicators of BBB permeability, which indicate the pharmacokinetic integrity of the BBB as a measure of nanotoxicity, many methods have been used to indicate toxicity to BBB anatomy and function. These assays most commonly focus on junction proteins mentioned above; claudins, occludin, and zonula occludens-1 $(15,16)$, or use electron microscopy (17).

In vitro BBB models are incomplete in their cell composition, cell interactions, cell spatial relationships, and degree of impermeability compared to the in vivo neurovascular unit. 
Therefore, the methods described in this chapter enable the in vivo determination of nanomaterial association with, and distribution across, the BBB with verification of brain (parenchymal, neuropil) entry.

There have been studies addressing brain entry of many nanomaterials with the conclusion that they get into the brain, which is different than crossing the BBB and entering brain tissue. For most studies the methods employed were not able to confirm nanomaterial distribution into brain parenchyma because they do not account for nanomaterial in the blood within the brain's vasculature or associated with BBB components. Rats perfused to remove blood $4 \mathrm{~h}$ after intravenous injection of gold glyconanoparticles had only $\sim 4 \%$ as much nanomaterial in their brain as rats that had not been perfused (18). Similarly, vascular perfusion reduced gold in three brain regions to 7 to $18 \%$ of that seen in non-perfused rats after intra-abdominal nanogold injection (19). Some studies accounted for the contribution of nanomaterial in blood to brain nanomaterial levels $(5,20,21)$, however this does not address nanomaterial in non-brain tissue sites such as adsorption to the luminal wall of brain vasculature or in cellular and membrane BBB components. After intravenous injection to rodents, nanomaterials were observed adhered to brain blood vessel walls with little to no evidence of brain tissue entry (22-24). These observations are in agreement with a kinetic study that reported a negatively charged nanoparticle associated with the cell surface, within seconds, by Langmuir adsorption through electrostatic interaction (25). In several studies, nanomaterial associated with brain at short-term time points did not persist to later times. The rapid decline of nanomaterial within a few hours in the whole brain or brain regions, 
e.g., $(19,26-33)$ can be interpreted as not reflecting brain tissue nanomaterial entry. This is because it would not be anticipated that nanomaterials, once taken up by brain cells, would be released and distribute from brain back into blood within this time. These results suggest that not all of the nanomaterial interpreted as entering the brain distributed into brain tissue. The nanomaterial may have adhered to the luminal wall of brain vasculature or localized in cellular or membrane components of the BBB, and subsequently distributed away from these sites into circulating blood and washed out of the brain. A few reports did verify nanomaterial brain tissue entry $(34,35)$. After whole body perfusion to remove blood, the capillary depletion method (described below) was used to separate brain parenchyma from brain capillaries. The percentage of the injected dose of $\left[{ }^{111}\right.$ In]DTPA-multiwalled carbon nanotubes decreased in brain capillaries, but not brain parenchyma over $24 \mathrm{~h}$, providing strong evidence of brain tissue entry of this nanomaterial (36).

The methods presented here assess whether a nanomaterial introduced into the vasculature perfusing the brain is associated with BBB components and/or crosses the BBB to enter brain tissue. Two methods are presented, the in situ brain perfusion technique and the capillary depletion method. They are best used together as the former provides a sample containing brain tissue as well as the vasculature within the brain. The latter separates BMECs from brain parenchymal tissue. The latter method is most often conducted with brain tissue obtained using the in situ brain perfusion technique, but can be used with brain tissue obtained by other methods. 
The in situ brain perfusion technique can be used to determine nanomaterial entry rate and extent of distribution into the brain, or multiple brain regions and/or the choroid plexus, ipsilateral to the carotid artery perfused after a short-term (few minutes or less) intra-carotid infusion of test material. It is particularly useful for materials that rapidly enter the brain, when the BBB has been opened intentionally, or in the presence of a disease that alters BBB integrity such as brain cancer. The intra-carotid perfusion rate is sufficient to prevent introduction of blood into the perfused carotid artery, therefore preventing blood from entering the brain hemisphere perfused by that artery. This enables control of the chemical environment of the material tested (therefore its chemical form [speciation]), based on the perfusion fluid composition and avoidance of exposure to blood. Avoiding blood exposure avoids potential nanomaterial biotransformation (e.g., corona coating by plasma proteins, dissolution, or particle breakdown) that might change its surface properties and brain uptake. Alternatively, the influence of coating the nanomaterial with plasma proteins or any other material could be investigated by their inclusion in the perfusion fluid.

The in situ brain perfusion technique includes the evaluation of BBB integrity based on determination of vascular volume and extracellular space. This is accomplished by inclusion in the perfusion fluid, by intravenous administration, or for IgG reliance on its presence in blood, of a BBB integrity marker (Table 1) that does not significantly distribute from blood to brain across the intact BBB during the time course of brain perfusion. 
The in situ brain perfusion technique can inform about the distribution of a nanomaterial out of the vascular compartment. It does not differentiate association with and distribution into BBB components from association with and uptake by brain cells.

The capillary depletion method was designed to remove the BMECs of the BBB from a brain homogenate to identify nanomaterial that trancytosed the BBB (capillary-depleted brain parenchyma). The goal is to determine nanomaterial distribution between the endothelial cells that contribute to brain capillaries vs. brain parenchyma to determine whether the nanomaterial entered brain parenchyma or if its distribution was limited to the BMECs. It is often utilized in conjunction with the in situ brain perfusion technique, but could be used after intravenous nanomaterial administration. The capillary depletion method was originally described by (37). It is a gradient centrifugation method using dextran ( density 1.07). As a result the BMECs are in the pellet (along with brain nuclei and erythrocytes if blood was not perfused from the brain) and the brain cells and brain extracellular fluid are in the supernatant. Given the observed association of nanomaterials with the luminal wall of BMECs $(23,24,38)$ this method can help to avoid the mistaken interpretation of results as nanomaterial brain entry, when the nanomaterial is associated with the BMECs, not having crossed the BBB.

In the original description of the in situ brain perfusion technique the occipital and superior thyroid arteries were coagulated or ligated and cut and the pterygopalatine artery was ligated and cut, because these arteries do not provide blood to the brain so perfusion fluid into the carotid artery that went into these arteries was "wasted" $(39,40)$. Perfusion fluid 
was delivered at 4 to $5 \mathrm{ml} / \mathrm{min}$ into the external carotid artery. This rate was chosen to minimize systemic blood flow to the contralateral hemisphere, maintain a carotid arterial perfusion pressure above the mean systolic pressure $(126 \mathrm{~mm} \mathrm{Hg})$, prevent blood from entering the internal carotid artery from the circle of Willis, and provide a pressure below 160 to $190 \mathrm{~mm} \mathrm{Hg}$, which was shown to damage the BBB. When perfusion was to exceed 1 minute a femoral artery was cannulated to enable blood withdrawal at the same rate as the carotid artery perfusion. There are many modifications of this method. We used a modification developed by the senior author of the original method $(37-41)$ that has the advantage of being less demanding of surgical skills and can be more rapidly accomplished (40). In this modification, the common carotid artery is cannulated followed by ligation of the external carotid artery. Ligation of the occipital, superior thyroid, and pterygopalatine arteries is optional. The heart is exposed and cardiac ventricles cut within 3 seconds before initiation of carotid artery perfusion. This is to terminate systemic circulation and the potential for blood to enter the perfused hemisphere and provide an outlet for the perfusion fluid delivered into the carotid artery. Due to perfusion fluid flow into these common carotid artery branches that do not perfuse the brain, the rate of perfusion fluid flow should be greater than $5 \mathrm{ml} / \mathrm{min}$. It can be varied because there is no systemic circulation providing an alternative blood source to the brain. Using this modification with ligation of only the pterygopalatine artery a perfusion rate of $10 \mathrm{ml} / \mathrm{min}$, and without ligation of the occipital, superior thyroid, and pterygopalatine arteries, 20 $\mathrm{ml} / \mathrm{min}$ was suggested (40). We used 15 and $20 \mathrm{ml} / \mathrm{min}$ flow rates that produced comparable vascular spaces (23).

\section{Materials}




\subsection{Both methods}

1. Ultrasonic bath/cleaner: Branson, Millipore Sigma, GT Sonic, others

2. Ability to sterilize by autoclaving, ethylene oxide, or in a glass bead dry sterilizer: Fine Science Tools, Germinator 500, Micro Bead Sterilizer, Steri 250, others

\subsection{The in situ brain perfusion technique}

\subsubsection{Anesthetic}

1. Injectable general anesthetic:
a. Ketamine: Henry Schein animal health
b. Xylazine: Henry Schein animal health, or dexmedetomidine: Henry Schein animal health
c. (see Note 1)
d. Plastic disposable luer-slip syringe (1 ml) and $25 \mathrm{~g}$ x 5/8" needle: (VWR, others)

2. Inhalation general anesthetic: Isoflurane: Isoflurane vaporizer, supply gas, and associated equipment

\subsubsection{Equipment and supplies}

1. Citranox ${ }^{\circledR}:$ Fisher Scientific, WWR

2. Absorbent pad: (VWR, others)

3. Sterile disposable drape/towel: (VWR, others)

4. Povidone-iodine (Betadine ${ }^{\circledR}$ : Fisher Scientific, VWR

5. Surgery board (optional), (see Note 2) 
6. Electric razor: Oster ${ }^{\circledR}$ Finisher ${ }^{\circledR}$ Narrow Blade Trimmer, Wahl from Braintree Scientific and Kent Scientific Corp.

7. Homeothermic heating blanket with rectal probe: 2Biological Instruments, E-Z anesthesia, Harvard Apparatus, Kent Scientific Corp., Stoelting

8. Scalpel handle and blade, scissors, microdissecting forceps, clamps: Fine Science Tools, George Tiemann \& Co., Roboz Surgical Instrument Co.

9. Bone rongeur, curved, $\sim 2$ mm cup: Fine Science Tools, George Tiemann \& Co., Roboz Surgical Instrument Co.

10. Flat stainless steel microspatula with rounded ends: Fisher Scientific

11. Stereo boom microscope with light source: AmScope, Fisher Scientific, Microscope.com, MicroscopeNet.com

12.4-0 silk thread: Fine Science Tools

13.PE 50 or PE 60 tubing: Fisher Scientific, Scientific Commodities Inc., Thomas Scientific

14. Heparin: Cardinal Health, Henry Schein animal health, Merritt, Pfizer

15. Plastic disposable luer-slip syringes, 1 and $5 \mathrm{ml}$, syringe needle, 20 gauge for PE-60, 23 gauge for PE-50 tubing (see Note 3)

16. Syringe pump capable of delivering 5 to $20 \mathrm{ml} / \mathrm{min}$ from a 20 to $60 \mathrm{ml}$ syringe: Cole-Parmer, Harvard Apparatus Pump 11 Elite Series or earlier (11, 22, 33, 44, PHD2000), kdScientific, New Era Pump Systems, Smiths Medical

17. Guillotine: Braintree Scientific, Nemi guillotine, or alternative method to rapidly remove the head from the body

18. Styrofoam block with well to hold dry or liquid ice 
19. Glass plate that lays over Styrofoam block

20. Perfusion fluid: The perfusion fluid composition may depend on the experimental goals and nanomaterial, but should be iso-osmotic, $\sim \mathrm{pH} 7.4$, and $37{ }^{\circ} \mathrm{C}$. We used a perfusion fluid of nanomaterial containing: $153 \mathrm{mM} \mathrm{Na}^{+}, 4.2 \mathrm{mM} \mathrm{K}^{+}, 1.5$ $\mathrm{mM} \mathrm{Ca}^{2+}, 0.9 \mathrm{mM} \mathrm{Mg}^{2+}, 162 \mathrm{mM} \mathrm{Cl}^{-}$, and $9 \mathrm{mM}$ glucose. Perfusion for more than a few minutes requires addition of oxygen-carrying capacity to the perfusion fluid. (see Note 4) This can be accomplished by addition of washed erythrocytes (40). However, this may change the nature of the nanomaterial by association with the erythrocytes (41-44). To determine BBB integrity, one of the BBB integrity markers in Table 1 can be added to the in situ brain perfusion fluid or given intravenously. Gadolinium can be quantified by elemental analysis, e.g. by ICPMS concurrently with the metal(s) of the nanomaterial if present. (see Note 5)

\subsection{The capillary depletion method}

\subsubsection{Equipment and supplies}

1. Buffer: $141 \mathrm{mM} \mathrm{NaCl}, 4 \mathrm{mM} \mathrm{KCl}, 2.8 \mathrm{mM} \mathrm{CaCl}_{2}, 1 \mathrm{mM} \mathrm{NaH}_{2} \mathrm{PO}_{4}, 1 \mathrm{mM} \mathrm{MgSO}_{4}$, $10 \mathrm{mM}$ glucose, and $10 \mathrm{mM}$ HEPES at $\mathrm{pH} 7.4$

2. Tenbroeck tissue grinder: Fisher Scientific, Wheaton Scientific

3. Dextran $70,000 \mathrm{~g} / \mathrm{mol}$ : Millipore Sigma

4. Swinging bucket refrigerated centrifuge with rotor capable of $5400 \times \mathrm{g}$ 


\section{Methods}

\subsection{Both methods:}

1. Clean instruments in an ultrasonic bath/cleaner after prior use.

2. Sterilize instruments.

3. Personnel should wear sterile gloves, wear proper clothing for laboratory work, and use personal protective equipment (if needed or required).

\subsection{In situ brain perfusion}

\subsubsection{Rat preparation}

1. Deeply anesthetize the rat following, if required, a governmentally and/or institutionally approved protocol.

a. With ketamine/xylazine (75 and $5 \mathrm{mg} / \mathrm{kg}$ ) or ketamine/dexmedetomidine (50 to 75 and $0.25 \mathrm{mg} / \mathrm{kg}$ ) given ip using a $25 \mathrm{~g} \mathrm{5/8"} \mathrm{needle,} \mathrm{supplemented} \mathrm{if} \mathrm{necessary}$ with ketamine $5 \mathrm{mg}$ ip, or other suitable injectable general anesthetic (see Note 1), or

b. With isoflurane ( 1 to $4 \%$ induction, 2 to $3 \%$ maintenance as needed), or other suitable inhalation general anesthetic.

2. Verify sufficient depth of anesthesia by lack of response to strong tail or foot pinch.

3. Maintain body temperature, typically by a homeothermic heating blanket with rectal probe. Alternatively maintain body temperature with a heating pad or lamp, monitored with a rectal thermometer.

3.2.2. Prepare the surgical work site.

1. Sterilize by spraying with Citranox ${ }^{\circledR}$ followed by $70 \%$ ethanol.

2. Lay down an absorbent pad. 
3. Place a sterile disposable drape/towel containing the sterilized instruments on the absorbent pad.

4. Drape non-procedure areas.

5. Place the anesthetized rat in dorsal recumbency (on its back). (see Note 2)

3.2.3. Cannulate the carotid artery.

1. Shave incision areas with clippers.

2. Swab incision areas with povidone-iodine.

3. Swab incision areas with $70 \%$ alcohol.

4. Expose one carotid artery (experimenter's choice), encircle it twice with surgical thread (4-0), one below the bifurcation, the other above, and tighten the thread on the one below the bifurcation (cardiac side) to prevent blood flow. (see Note 6)

5. Insert sterile (see Note 7) PE 50 or PE 60 tubing containing heparin (100 U/mL) in $0.9 \% \mathrm{NaCl}$ into the common carotid, 4 to $5 \mathrm{~mm}$ above the bifurcation of the common carotid artery and secure it in the artery by a thread knot around the artery and indwelling tubing.

6. To contain blood released from the ligated heart, place the rat in a perfusion tray or on a grid over a sink.

7. Expose the heart by cutting through the skin and underlying tissue with a scissors in a caudal to rostral direction from the abdomen just below the xyphoid process (opening the peritoneal cavity), in a mid-line incision, up through the ventral thoracic cavity (opening it), avoiding lung, heart and mammary arteries. Cut the right atrial chamber or vena cava with scissors. 
8. Deliver the perfusion fluid (see Note 8) using a pump and preferably a glass syringe (see notes 9 to 16 ).

9. Decapitate the rat to end the perfusion.

10. Harvest the brain by cutting the scalp midline with a scalpel blade down to the cranium and pulling the skin to the sides. Using a bone rongeur, starting at the base of the skull, remove the skull from over the brain to expose the brain, being careful to not remove brain tissue. Cut the dura mater with the scalpel blade and pull it away from the brain. Use a flat stainless steel microspatula with rounded ends to get under the brain, cut the cranial nerves, and lift the brain from the cranial vault.

11. Place the brain sample on the cooled, moist, glass plate over the Styrofoam block containing ice.

12. Remove the meninges and surface vessels from the brain's surface with microforceps.

13. Dissect the desired brain region (typically forebrain) or regions from perfused hemisphere away from the rest of the brain and, if relevant to the brain region isolated, remove the lateral ventricle choroid plexus from the sample. (see Note 17).

14. Retain a sample of the perfusion fluid for nanomaterial concentration analysis and quantitation of the BBB integrity/vascular volume/extracellular space marker.

15. Quantify the nanomaterial and BBB integrity/vascular volume/extracellular space marker in the brain sample or brain regions and perfusion fluid sample. 


\subsection{The capillary depletion method}

1. After nanomaterial dosing by carotid arterial perfusion of the in situ brain perfusion technique or any other route, blood should be perfused out of the brain before the brain is harvested. This is accomplished by systemic perfusion of the animal to remove blood from within the brain that contains nanomaterial.

2. Homogenize the tissue in $3.5 \mathrm{ml}$ ice-cold buffer with 8 to 10 strokes in a Tenbroeck tissue grinder. Add dextran $(70,000 \mathrm{~g} / \mathrm{mol})$ to $18 \%(\mathrm{w} / \mathrm{v})$ and further homogenize the sample with five additional strokes.

3. Remove an aliquot of the homogenate for determination of nanomaterial content.

4. Centrifuge the sample at $5400 \times \mathrm{g}$ for $15 \mathrm{~min}$ in a swinging bucket centrifuge at 4 ${ }^{\circ} \mathrm{C}$.

5. Carefully separate the supernatant (brain rich fraction) and pellet (capillary rich fraction) for nanomaterial measurement in each fraction. (see Note 18)

\subsection{Data analysis and interpretation of results}

\subsubsection{In situ brain perfusion}

Flow-rate-dependent uptake is a property of some carrier-mediated transporters, but not diffusion. To identify the process of nanomaterial brain uptake, the effect of perfusion flow rate on influx rate can be determined. Diffusion-mediated nanomaterial brain uptake should be concentration independent, whereas the capacity of a carrier-mediated transporter may be exceeded. The uptake process can be further investigated by varying the nanomaterial concentration, to determine if the uptake space (see below) becomes saturated. This would not be expected for diffusion-mediated uptake during the short 
perfusion duration of the typical in situ perfusion experiment. Perfusion fluid flow rate- and nanomaterial concentration-dependent brain uptake would suggest non-diffusionmediated uptake.

The influx rate $\left(\mathrm{K}_{\mathrm{in}}\right)$ is the rate of nanomaterial influx in a given time into a given amount (space) of brain. It is the quotient of uptake space $(Q)$ over time. $K_{\text {in }}$ reflects the volume of perfusion fluid cleared of nanomaterial which is transferred into a specific mass (typically expressed per gram) of brain over a given time period. It can be determined by using multiple perfusion times, and generation of a graph of the linear least squares regression of the corrected uptake space (Qnanomaterial) vs. perfusion time, assuming the ANOVA of corrected uptake space vs. time shows linearity. The slope of the regression line is an estimate of $K_{\text {in. }}$ The uptake space ( $\left.Q_{\text {nanomaterial }}\right)$, or distribution volume, derived from the in situ brain perfusion results (Qnanomaterial total), is the brain tissue mass into which the nanomaterial distributes during a given perfusion duration. (see note 19). Qnanomaterial total is expressed as $\mathrm{ml} / \mathrm{g}$ brain, and calculated as in eq $1(39)$ :

eq.1

mass of nanomaterial per weight brain tissue $(\mathrm{g} / \mathrm{g}) /$

the mass of nanomaterial per volume of perfusate $(\mathrm{g} / \mathrm{ml})$

The uptake space is corrected for the sample's vascular/extracellular space by subtracting the uptake space of the vascular volume/extracellular space marker calculated as in eq. 2 (obtained with a substance in Table 1), to give the corrected uptake space, calculated as in eq 3 , and used to calculate $\mathrm{K}_{\text {in. }}$. 
eq. 2

vascular/extracellular space marker (g/g) / vascular/ extracellular space marker per volume of perfusate $(\mathrm{g} / \mathrm{ml})$

eq.3

\author{
$Q$ nanomaterial $=Q$ nanomaterial total - \\ Qvascular/extracellular space marker
}

\title{
3.4.2. The capillary depletion method
}

The percentage of nanomaterial in the capillary-enriched fraction is determined as: (nanomaterial mass in the capillary-enriched fraction normalized to the whole brain / nanomaterial mass in the homogenized brain aliquot normalized to the whole brain) $x$ $100 \%$.

Mass balance can be calculated by comparing the sum of the nanomaterial in the capillary-enriched fraction normalized to the whole brain (or brain sample) plus nanomaterial in the capillary-depleted-fraction normalized to the whole brain (or brain sample), compared to the nanomaterial in the aliquot of the homogenized brain normalized to the whole brain (or brain sample). 


\section{Notes}

1. There are now and will be in the future many suitable alternatives to this combination.

2. The operator may want to restrain the rat on a surgery board: Harvard Apparatus, Plas-Labs, Inc.

3. Dull the tip of needles to be inserted into PE tubing to reduce sticking oneself with the needle and puncturing the tubing while inserting the needle in the tubing. This can be done with a file, being careful to not occlude the needle lumen. Inserting stainless steel wire in the needle lumen helps avoid occlusion. The inner diameter of a 20 gauge needle is $0.34 \mathrm{~mm}$ and of a 23 gauge needle is 0.6 $\mathrm{mm}$.

4. Introducing oxygen-carrying capacity to the perfusion fluid can be accomplished by addition of washed erythrocytes (40) or blood substitute. However, erythrocyte association may change the nature of the nanomaterial (41-44).

5. Sucrose, and perhaps some of the other markers, is a source for microorganism metabolism. If not maintained sterile it can be catabolized and the results of its use to determine the vascular space would not be valid.

6. Some videos showing carotid artery isolation are available:

https://www.bing.com/videos/search?q=youtube+of+rat+carotid+artery+cannulati on\&view=detail\&mid=5C689127E36E8933C4AA5C689127E36E8933C4AA\&FO $\underline{\mathrm{RM}=\mathrm{VIRE} ; \text { https://www.youtube.com/watch?v=a cdEJHRiVs; }}$ https://www.youtube.com/watch?v=QoGmUSOJSoM; https://www.jove.com/video/51881/catheterization-carotid-artery-jugular-vein-toperform-hemodynamic 
7. PE tubing can be sterilized by ethylene oxide or $70 \%$ ethanol immersion. Autoclaving should not be used as it melts the tubing. Tubing insertion into the carotid artery was facilitated when the artery was partially cut at an angle and the tubing end was beveled.

8. Following at least $1 \mathrm{~h}$ incubation at $37^{\circ} \mathrm{C}$, the perfusion fluid is bubbled for 2 minutes with $95 / 5$ air/ $\mathrm{CO}_{2}$ and adjusted to $\mathrm{pH} 7.4$. The perfusion fluid should be used as soon as possible, at $37^{\circ} \mathrm{C}$. Maintained at $37^{\circ} \mathrm{C}$ perfusion fluid $\mathrm{pH}$ was shown to be stable for $4 \mathrm{~h}(45)$.

9. Delivery of perfusion fluid in the in situ brain perfusion technique is best accomplished using glass, rather than plastic syringes, due to lower friction of the former. Sources of glass syringes and plungers include Becton Dickinson, Hamilton 1000 series gastight syringe, Harvard Apparatus Yale Glass Syringe with Robb Tip, Leur-Loc.

10. Nanomaterials rapidly associate with proteins in blood. Protein coating, the corona, can greatly influence the nanomaterial surface properties, and "what the cell sees" (46). The use of a blood/plasma/serum-free perfusion fluid delivering the nanomaterial to the brain in the in situ brain perfusion procedure reduces the potential for significant change to its surface chemistry, compared to its delivery to the brain in blood or blood components. Uncoated nanomaterials tend to rapidly agglomerate in the presence of ions in the surrounding solution. Nanomaterials are typically surface coated to reduce agglomeration. When the in situ brain perfusion procedure is used it would be wise to determine if the nanomaterial agglomerates in the perfusion fluid during its exposure time. 
11. If there is concern that nanomaterial properties would be significantly affected by contact with blood at the beginning of the perfusion, nanomaterial-free perfusion fluid could be delivered before initiation of nanomaterial-containing perfusion fluid.

12. The duration of in situ perfusion is generally no more than 2 minutes to avoid anoxic injury to the BBB and brain, unless an oxygen-providing source is added to the perfusion fluid. (see Note 4)

13. The "dead" volume of the carotid infusion cannula that is not filled with nanomaterial-containing perfusion fluid that will be delivered to the brain before the nanomaterial-containing perfusion fluid must be considered when determining the infusion time and amount of nanomaterial delivered to the brain. One approach is to add sufficient time to the perfusion to displace the non-nanomaterial-containing perfusion fluid and to deliver the entire intended volume of test substancecontaining perfusion fluid. A better approach is to deliver the entire volume of test substance in perfusion fluid to the brain then follow its infusion with nanomaterialfree perfusion fluid, as discussed in the next note.

14. After perfusion fluid administration, cerebrovascular washout of the perfusion fluid should be conducted to remove the contribution of nanomaterial in the vascular space to apparent brain uptake. This can be conducted by perfusion of nanomaterial-free perfusion fluid for 5 to 20 seconds at the same rate as used to deliver the perfusion fluid, immediately following perfusion of the nanomaterialcontaining perfusion fluid.(47) 
15. The rapid change from nanomaterial-containing to nanomaterial-free perfusion fluid can be accomplished with a 4-way stopcock, e.g. BD M4018, BD 394910, B. Braun 455991, B. Braun 456003, B. Braun 457501.

16. For small molecules that might back diffuse from brain to blood, or substances that might be transported in that direction after entering the brain, efflux will reduce apparent brain uptake. The longer the time before decapitation including perfusion duration, the greater the potential for efflux. For nanomaterials, that are not expected to be released from cells after their uptake by phagosomes and incorporation into phagolysosomes, this should not be a concern.

17. Specific brain regions can be harvested by sectioning the brain in an acrylic matrice (Braintree Scientific, Inc.) to $1 \mathrm{~mm}$ thick sections with a razor blade and placing the sections on the glass plate over ice in the well of a Styrofoam block. Ice keeps the glass cold and moist, avoiding brain sticking to the glass. Specific brain regions can be dissected from the slices with guidance from a rat brain atlas (e.g., (48), http://labs.gaidi.ca/rat-brain-atlas/). When regional variation is to be studied, brain tissue is often collected from the frontal cortex, parietal cortex, occipital cortex, thalamus/hypothalamus, midbrain/colliculus, striatum, cerebellum, hippocampus, and choroid plexus. The weight of each sample is obtained in a pre-weighed vessel.

18. The separation should produce much higher activity of alkaline phosphatase and g-glutamyltransferase activity, capillary-specific enzymes, in the capillaryenriched fraction. They can be determined using enzyme activity kits (Millipore 
Sigma). Microscopic examination should also confirm the presence of capillary fragments in the capillary-enriched fraction, but not the capillary-poor fraction.

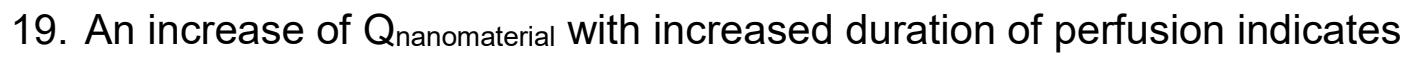
nanomaterial association with BMECs and/or brain entry. It does not unequivocally demonstrate brain parenchyma entry. To determine this, the capillary depletion method can be used. One alternative to the capillary depletion method to confirm brain parenchyma nanomaterial uptake for electron dense nanomaterials is electron microscopy (and for metal-containing nanomaterials elemental analysis, such as energy-dispersive X-ray spectroscopy), to qualitatively demonstrate brain parenchyma uptake. 


\section{References}

1. Sanovich E, Bartus RT, Friden PM, Dean RL, Le HQ, Brightman MW (1995) Pathway across blood-brain barrier opened by the bradykinin agonist, RMP-7. Brain Res $705: 125-135$

2. Zlokovic BV, Apuzzo ML (1998) Strategies to circumvent vascular barriers of the central nervous system. Neurosurgery 43:877-878

3. Boström M, Hellstroem Erkenstam N, Kaluza D, Jakobsson L, Kalm M, Blomgren K (2014) The hippocampal neurovascular niche during normal development and after irradiation to the juvenile mouse brain. Int J Radiat Biol 90:778-789

4. Ohno K, Pettigrew KD, Rapoport SI (1978) Lower limits of cerebrovascular permeability to nonelectrolytes in the conscious rat. Am J Physiol 235:H299$\mathrm{H} 307$

5. Calvo P, Gouritin B, Chacun H, Desmaele D, D'Angelo J, Noel JP, Georgin D, Fattal E, Andreux JP, Couvreur P (2001) Long-circulating PEGylated polycyanoacrylate nanoparticles as new drug carrier for brain delivery. Pharm Res 18:1157-1166

6. Levin VA (1980) Relationship of octanol/water partition coefficient and molecular weight to rat brain capillary permeability. J Med Chem 23:682-684

7. Laterra J, Keep R, Betz AL, Goldstein GW (1999) Blood-brain-cerebrospinal fluid barriers. In: Siegel GJ, Agranoff BW (eds.) Basic neurochemistry: Molecular, cellular and medical aspects. pp. 671-689. Lippincott-Raven Publishers, Philadelphia

8. Pardridge WM (2012) Drug transport across the blood-brain barrier. J Cereb Blood Flow Metab 32:1959-1972 
9. Yokel RA (2006) Blood-brain barrier flux of aluminum, manganese, iron and other metals suspected to contribute to metal-induced neurodegeneration. $\mathrm{J}$ Alzheimer's Dis 10:223-253

10. Yokel RA, Grulke EA, MacPhail RC (2013) Metal-based nanoparticle interactions with the nervous system: the challenge of brain entry and the risk of retention in the organism. Wiley Interdiscip Rev Nanomed Nanobiotechnol 5:346-373

11. Madhusoodanan J (2016) Designing in vitro models of the blood-brain barrier. The Scientist, September 1

12. Mantle JL, Min L, Lee KH (2016) Minimum transendothelial electrical resistance thresholds for the study of small and large molecule drug transport in a human in vitro blood-brain barrier model. Mol Pharmaceut 13:4191-4198

13. Abbott NJ, Dolman DEM, Drndarski S, Fredriksson SM (2012) An improved in vitro blood-brain barrier model: rat brain endothelial cells co-cultured with astrocytes. Methods Mol Biol 814:415-430

14. Butt AM, Jones HC, Abbott NJ (1990) Electrical resistance across the blood-brain barrier in anaesthetized rats: a developmental study. J Physiol 429:47-62

15. Disdier C, Devoy J, Cosnefroy A, Chalansonnet M, Herlin-Boime N, Brun E, Lund A, Mabondzo A (2015) Tissue biodistribution of intravenously administrated titanium dioxide nanoparticles revealed blood-brain barrier clearance and brain inflammation in rat. Part Fibre Toxicol 12:27/21-27/20

16. Mendonca MCP, Soares ES, de Jesus MB, Ceragioli HJ, Batista AG, Nyul-Toth A, Molnar J, Wilhelm I, Marostica MR, Krizbai I, da Cruz-Hofling MA (2016) 
PEGylation of reduced graphene oxide induces toxicity in cells of the blood-brain barrier: An in vitro and in vivo study. Mol Pharmaceut 13:3913-3924

17. Yokel RA, Florence RL, Unrine JM, Tseng MT, Graham UM, Wu P, Grulke EA, Sultana R, Hardas SS, Butterfield DA (2009) Biodistribution and oxidative stress effects of a systemically-introduced commercial ceria engineered nanomaterial. Nanotoxicology 3:234-248

18. Frigell J, Garcia I, Gomez-Vallejo V, Llop J, Penades S (2014) ${ }^{68}$ Ga-labeled gold glyconanoparticles for exploring blood-brain barrier permeability: Preparation, biodistribution studies, and improved brain uptake via neuropeptide conjugation. J Am Chem Soc 136:449-457

19. Sela H, Elia P, Zach R, Zeiri Y, Sela H, Karpas Z, Zeiri Y, Cohen H (2015) Spontaneous penetration of gold nanoparticles through the blood brain barrier (BBB). J Nanobiotech 13:71

20. Schleh C, Semmler-Behnke M, Lipka J, Wenk A, Hirn S, Schaeffler M, Schmid G, Simon U, Kreyling WG (2012) Size and surface charge of gold nanoparticles determine absorption across intestinal barriers and accumulation in secondary target organs after oral administration. Nanotoxicology 6:36-46

21. Buzulukov YP, Arianova EA, Demin VF, Safenkova IV, Gmoshinski IV, Tutelyan VA (2014) Bioaccumulation of silver and gold nanoparticles in organs and tissues of rats studied by neutron activation analysis. Biol Bull (Moscow, Russ. Fed.) $41: 255-263$

22. Gessner A, Olbrich C, Schroder W, Kayser O, Muller RH (2001) The role of plasma proteins in brain targeting: species dependent protein adsorption patterns on 
brain-specific lipid drug conjugate (LDC) nanoparticles. Int J Pharmaceut 214:8791

23. Dan M, Tseng MT, Wu P, Unrine JM, Grulke EA, Yokel RA (2012) Brain microvascular endothelial cell association and distribution of a $5 \mathrm{~nm}$ ceria engineered nanomaterial. Int J Nanomed 7:4023-4036

24. Baghirov H, Karaman D, Viitala T, Duchanoy A, Lou Y-R, Mamaeva V, Pryazhnikov E, Khiroug L, Davies CdL, Sahlgren C, Rosenholm JM (2016) Feasibility study of the permeability and uptake of mesoporous silica nanoparticles across the bloodbrain barrier. PLoS One 11:e0160705/0160701-e0160705/0160722

25. Wilhelm C, Gazeau F, Roger J, Pons JN, Bacri JC (2002) Interaction of anionic superparamagnetic nanoparticles with cells: kinetic analyses of membrane adsorption and subsequent internalization. Langmuir 18:8148-8155

26. Gao K, Jiang X (2006) Influence of particle size on transport of methotrexate across blood brain barrier by polysorbate 80 -coated polybutylcyanoacrylate nanoparticles. Int J Pharmaceut 310:213-219

27. Al Zaki A, Hui JZ, Higbee E, Tsourkas A (2015) Biodistribution, clearance, and toxicology of polymeric micelles loaded with 0.9 or $5 \mathrm{~nm}$ gold nanoparticles. $\mathrm{J}$ Biomed Nanotechnol 11:1836-1846

28. Tsai Y-M, Chien C-F, Lin L-C, Tsai T-H (2011) Curcumin and its nano-formulation: The kinetics of tissue distribution and blood-brain barrier penetration. Int $\mathrm{J}$ Pharmaceut 416:331-338 
29. Tröster SD, Müller U, Kreuter J (1990) Modification of the body distribution of poly(methyl methacrylate) nanoparticles in rats by coating with surfactants. Int $\mathrm{J}$ Pharmaceut 61:85-100

30. Fundarò A, Cavalli R, Bargoni A, Vighetto D, Zara GP, Gasco MR (2000) Nonstealth and stealth solid lipid nanoparticles (SLN) carrying doxorubicin: pharmacokinetics and tissue distribution after i.v. administration to rats. Pharmacol Res 42:337-343

31. Guerrero S, Araya E, Fiedler JL, Arias JI, Adura C, Albericio F, Giralt E, Arias JL, Fernandez MS, Kogan MJ (2010) Improving the brain delivery of gold nanoparticles by conjugation with an amphipathic peptide. Nanomedicine (London, U. K.) 5:897-913

32. Wen Z, Yan Z, He R, Pang Z, Guo L, Qian Y, Jiang X, Fang L (2011) Brain targeting and toxicity study of odorranalectin-conjugated nanoparticles following intranasal administration. Drug Delivery 18:555-561

33. Martins SM, Sarmento B, Nunes C, Lucio M, Reis S, Ferreira DC (2013) Brain targeting effect of camptothecin-loaded solid lipid nanoparticles in rat after intravenous administration. Eur J Pharm Biopharm 85:488-502

34. Chen Y-S, Hung Y-C, Lin L-W, Liau I, Hong M-Y, Huang GS (2010) Size-dependent impairment of cognition in mice caused by the injection of gold nanoparticles. Nanotechnol 21:485102/485101-485102/485109

35. Dziendzikowska K, Gromadzka-Ostrowska J, Lankoff A, Oczkowski M, Krawczynska A, Chwastowska J, Sadowska-Bratek M, Chajduk E, Wojewodzka 
M, Dusinska M, Kruszewski M (2012) Time-dependent biodistribution and excretion of silver nanoparticles in male Wistar rats. J Appl Toxicol 32:920-928

36. Kafa H, Wang JT-W, Rubio N, Venner K, Anderson G, Pach E, Ballesteros B, Preston JE, Abbott NJ, Al-Jamal KT (2015) The interaction of carbon nanotubes with an in vitro blood-brain barrier model and mouse brain in vivo. Biomaterials $53: 437-452$

37. Triguero D, Buciak J, Pardridge WM (1990) Capillary depletion method for quantification of blood-brain barrier transport of circulating peptides and plasma proteins. J Neurochem 54:1882-1888

38. Gessner A, Olbrich C, Schroder W, Kayser O, Muller RH (2001) The role of plasma proteins in brain targeting: species dependent protein adsorption patterns on brain-specific lipid drug conjugate (LDC) nanoparticles. Int J Pharm 214:87-91

39. Takasato Y, Rapoport SI, Smith QR (1984) An in situ brain perfusion technique to study cerebrovascular transport in the rat. Am J Physiol 247:H484-H493

40. Smith QR (1996) Brain perfusion systems for studies of drug uptake and metabolism in the central nervous system. Pharmaceut Biotech 8:285-307

41. Geiser M, Rothen-Rutishauser B, Kapp N, Schurch S, Kreyling W, Schulz H, Semmler M, Im Hof V, Heyder J, Gehr P (2005) Ultrafine particles cross cellular membranes by nonphagocytic mechanisms in lungs and in cultured cells. Environ Health Perspect 113:1555-1560

42. Wang J, Zhou G, Chen C, Yu H, Wang T, Ma Y, Jia G, Gao Y, Li B, Sun J, Li Y, Jiao F, Zhao Y, Chai Z (2007) Acute toxicity and biodistribution of different sized 
titanium dioxide particles in mice after oral administration. Toxicol Lett 168:176185

43. Nemmar A, Beegam S, Yuvaraju P, Yasin J, Shahin A, Ali BH (2014) Interaction of amorphous silica nanoparticles with erythrocytes in vitro: Role of oxidative stress. Cell Physiol Biochem 34:255-265

44. Antonelli A, Sfara C, Manuali E, Bruce IJ, Magnani M (2011) Encapsulation of superparamagnetic nanoparticles into red blood cells as new carriers of MRI contrast agents. Nanomedicine (London, U. K.) 6:211-223

45. Crossgrove JS, Allen DD, Bukaveckas BL, Rhineheimer SS, Yokel RA (2003) Manganese distribution across the blood-brain barrier. I. Evidence for carriermediated influx of managanese citrate as well as manganese and manganese transferrin. NeuroToxicology 24:3-13

46. Walczyk D, Bombelli FB, Monopoli MP, Lynch I, Dawson KA (2010) What the cell "sees" in bionanoscience. J Am Chem Soc 132:5761-5768

47. Crossgrove JS, Yokel RA (2004) Manganese distribution across the blood-brain barrier III. The divalent metal transporter-1 is not the major mechanism mediating brain manganese uptake. Neurotoxicology 25:451-460

48. Paxinos G, Charles W (2013) The rat brain in stereotaxic coordinates, 7th ed. Academic Press, Cambridge, MA

49. Weyerbrock A, Walbridge S, Saavedra JE, Keefer LK, Oldfield EH (2011) Differential effects of nitric oxide on blood-brain barrier integrity and cerebral blood flow in intracerebral C6 gliomas. Neuro-Oncology 13:203-211 
50. Blasberg RG, Fenstermacher JD, Patlak CS (1983) Transport of $\alpha$-aminoisobutyric acid across brain capillary and cellular membranes. J Cereb Blood Flow Metab $3: 8-32$

51. Alaofi A, On N, Kiptoo P, Williams TD, Miller DW, Siahaan TJ (2016) Comparison of linear and cyclic his-ala-val peptides in modulating the blood-brain barrier permeability: Impact on delivery of molecules to the brain. J Pharm Sci 105:797807

52. Laksitorini MD, Kiptoo PK, On NH, Thliveris JA, Miller DW, Siahaan TJ (2015) Modulation of intercellular junctions by cyclic-ADT peptides as a method to reversibly increase blood-brain barrier permeability. J Pharm Sci 104:1065-1075

53. Sisson WB, Oldendorf WH (1971) Brain distribution spaces of mannitol- ${ }^{3} \mathrm{H}$, inulin${ }^{14} \mathrm{C}$, and dextran- ${ }^{-14} \mathrm{C}$ in the rat. Amer J Physiol 221:214-217

54. Hawkins BT, Egleton RD (2006) Fluorescence imaging of blood-brain barrier disruption. J Neurosci Meth 151:262-267

55. Euser AG, Bullinger L, Cipolla MJ (2008) Magnesium sulphate treatment decreases blood-brain barrier permeability during acute hypertension in pregnant rats. Exp Physiol 93:254-261

56. Smith QR, Ziylan YZ, Robinson PJ, Rapoport SI (1988) Kinetics and distribution volumes for tracers of different sizes in the brain plasma space. Brain Res 462:19

57. Wolff CB, Sarker MH, Fraser PA (1995) Cerebral microvascular permeability and CSF pH in anaesthetized rats. Exp Physiol 80:1053-1055 
58. Miller RD, Monsul NT, Vender JR, Lehmann JC (1996) NMDA- and endothelin-1induced increases in blood-brain barrier permeability quantitated with Lucifer yellow. J Neurol Sci 136:37-40

59. Tabanor K, Lee P, Kiptoo P, Choi I-Y, Sherry EB, Eagle CS, Williams TD, Siahaan TJ (2016) Brain delivery of drug and MRI contrast agent: Detection and quantitative determination of brain deposition of CPT-glu using LC-MS/MS and Gd-DTPA using magnetic resonance imaging. Mol Pharmaceut 13:379-390

60. Alyaudtin RN, Reichel A, Lobenberg R, Ramge P, Kreuter J, Begley DJ (2001) Interaction of poly(butyl cyanoacrylate) nanoparticles with the blood-brain barrier in vivo and in vitro. J Drug Targeting 9:209-221

61. Carvey PM, Zhao CH, Hendey B, Lum H, Trachtenberg J, Desai BS, Snyder J, Zhu YG, Ling ZD (2005) 6-Hydroxydopamine-induced alterations in blood-brain barrier permeability. Eur J Neurosci 22:1158-1168

62. Bertram KJ, Shipley MT, Ennis M, Sanberg PR, Norman AB (1994) Permeability of the blood-brain barrier within rat intrastriatal transplants assessed by simultaneous systemic injection of horseradish peroxidase and Evans blue dye. Exp Neurol 127:245-252

63. Hoffmann A, Bredno J, Wendland M, Derugin N, Ohara P, Wintermark M (2011) High and low molecular weight fluorescein isothiocyanate (FITC)-dextrans to assess blood-brain barrier disruption: Technical considerations. Transl Stroke Res 2:106-111

64. Shim KH, Jeong K-H, Bae SO, Kang MO, Maeng EH, Choi CS, Kim Y-R, Hulme J, Lee EK, Kim M-K, An SSA (2014) Assessment of $\mathrm{ZnO}$ and $\mathrm{SiO}_{2}$ nanoparticle 
permeability through and toxicity to the blood-brain barrier using Evans blue and TEM. Int J Nanomed 9:225-233

65. Zhang J, Ke K-F, Liu Z, Qiu Y-H, Peng Y-P (2013) Th17 cell-mediated neuroinflammation is involved in neurodegeneration of $A \beta 1-42$-induced Alzheimer's disease model rats. PLoS One 8:e75786

66. Michalski D, Grosche J, Pelz J, Schneider D, Weise C, Bauer U, Kacza J, Gaertner U, Hobohm C, Haertig W (2010) A novel quantification of blood-brain barrier damage and histochemical typing after embolic stroke in rats. Brain Res 1359:186-200

67. Pinard E, Engrand N, Seylaz J (2000) Dynamic cerebral microcirculatory changes in transient forebrain ischemia in rats: involvement of type I nitric oxide synthase. $\mathrm{J}$ Cereb Blood Flow Metab 20:1648-1658

68. Li Y, Xu L, Zeng K, Xu Z, Suo D, Peng L, Ren T, Sun Z, Yang W, Jin X, Yang L (2017) Propane-2-sulfonic acid octadec-9-enyl-amide, a novel PPARa/y dual agonist, protects against ischemia-induced brain damage in mice by inhibiting inflammatory responses. Brain Behav Immun 66:289-301

69. Jacob A, Hack B, Chiang E, Garcia JGN, Quigg RJ, Alexander JJ (2010) C5a alters blood-brain barrier integrity in experimental lupus. FASEB J 24:1682-1688 
Table 1. Substances to quantify BBB permeability (or its reciprocal, integrity) and to determine the volume of the vascular and extracellular spaces of the perfusion fluidcontaining test substance (nanomaterial) in harvested brain tissue. The table lists substances in ascending order of their size and some commonly used quantification methods.

\begin{tabular}{|c|c|c|c|}
\hline Substance & Size $\left(D_{a}\right)$ & $\begin{array}{c}\text { Concentration in } \\
\text { intra-carotid } \\
\text { perfusion fluid }{ }^{1} \\
\text { Intravenous } \\
\text { concentration or } \\
\text { dose }^{2}\end{array}$ & $\begin{array}{c}\text { Quantification } \\
\text { method(s) }\end{array}$ \\
\hline $\begin{array}{l}{ }^{3} \mathrm{H}-\text { or }{ }^{14} \mathrm{C}-\alpha-a m i n o \\
\text { isobutyric acid }\end{array}$ & 103 & $\begin{array}{c}{ }^{3} \mathrm{H} 1 \text { or }{ }^{14} \mathrm{C} 0.5 \\
\mu \mathrm{Ci} / \mathrm{ml}^{1} \\
{ }^{14} \mathrm{C} 10 \text { to } 80 \mu \mathrm{Ci}^{2}(49, \\
50)\end{array}$ & Radiation counting \\
\hline${ }^{3} \mathrm{H}$ - or D- $\left[{ }^{1-14} \mathrm{C}\right]$ mannitol & 182 & $\begin{array}{c}{ }^{3} \mathrm{H} 1 \text { or }{ }^{14} \mathrm{C} 0.5 \\
\mu \mathrm{Ci} / \mathrm{ml}, 10 \mu \mathrm{Ci}^{1} \\
(51,52) \\
{ }^{3} \mathrm{H} 15 \mu \mathrm{Ci}^{2}(53)\end{array}$ & Radiation counting \\
\hline fluorescein & 334 & $\begin{array}{l}0.1 \%^{1}(54) \\
0.1 \%^{2}(55)\end{array}$ & $\begin{array}{l}\text { Fluorescence (excitation } \\
\lambda_{\max } 493 \mathrm{~nm} \text {, emission } \\
\left.\lambda_{\max } 514 \mathrm{~nm}\right)\end{array}$ \\
\hline${ }^{3} \mathrm{H}$ - or U-14 C-sucrose & 342 & $\begin{array}{c}{ }^{3} \mathrm{H} 1 \text { or }{ }^{14} \mathrm{C} 0.5 \\
\mu \mathrm{Ci} / \mathrm{ml}^{1} \\
{ }^{14} \mathrm{C} 10 \text { to } 80 \mu \mathrm{Ci}^{2}(49, \\
56)\end{array}$ & Radiation counting \\
\hline lucifer yellow & 457 & $\begin{array}{l}5 \mathrm{mM}^{1}(57) \\
25 \mathrm{mg}^{2}(58)\end{array}$ & $\begin{array}{l}\text { Fluorescence (excitation } \\
\lambda_{\max } 380 \mathrm{~nm} \text {, emission } \\
\left.\lambda_{\max } 542 \mathrm{~nm}\right)\end{array}$ \\
\hline $\begin{array}{l}\text { gadolinium- } \\
\text { diethylenetriamine } \\
\text { pentaacetic acid } \\
\text { (DTPA) complex }\end{array}$ & 938 & $\begin{array}{l}0.6 \mathrm{mmol} / \mathrm{kg}^{1}(59) \\
0.4 \mathrm{mmol} / \mathrm{kg}^{2}(51)\end{array}$ & $\begin{array}{l}\text { MRI or Gd ICP-MS } \\
\text { elemental analysis }\end{array}$ \\
\hline${ }^{3} \mathrm{H}$ - or U-14 C-inulin & $\begin{array}{l}\sim 5000- \\
5500\end{array}$ & $\begin{array}{c}{ }^{3} \mathrm{H} 1 \text { or }{ }^{14} \mathrm{C} 0.5 \\
\mu \mathrm{Ci} / \mathrm{ml}^{1}(39) \\
{ }^{1} \mathrm{H} 30 \text { to } 50 \mu \mathrm{Ci}^{2} \\
(56,60) \\
{ }^{14} \mathrm{C} 4 \mu \mathrm{Ci}^{2}(53)\end{array}$ & Radiation counting \\
\hline carboxyl- $\left[{ }^{14} \mathrm{C}\right]$-inulin & $\sim 6200$ & $0.5 \mu \mathrm{Ci} / \mathrm{ml}^{1}$ & Radiation counting \\
\hline horseradish peroxidase & 44,000 & $\begin{array}{c}2.5 \mathrm{mg} / \mathrm{min}^{1}(61) \\
34 \mathrm{mg} / \mathrm{kg}^{2}(62)\end{array}$ & $\begin{array}{l}\text { Forms a brown reaction } \\
\text { product with } \\
\text { diaminobenzidine ( } \lambda \max \\
465) \text { or a blue product } \\
\text { with o-dianisidine ( } \lambda \text { max } \\
460 \mathrm{~nm} \text { ) }\end{array}$ \\
\hline
\end{tabular}




\begin{tabular}{|c|c|c|c|}
\hline $\begin{array}{l}\text { Evan's blue + albumin } \\
\text { complex }\end{array}$ & $\sim 66,000$ & $\begin{array}{c}0.1 \% \text { Evan's blue }{ }^{1} \\
(54) \\
2 \% \text { Evan's blue }{ }^{2} \\
(63,64)\end{array}$ & $\begin{array}{l}\text { VIS spectroscopy ( } \lambda \max \\
609,635 \mathrm{~nm} \text {; Evan's } \\
\text { blue) } \\
\text { immunocytochemistry } \\
\text { (albumin) }\end{array}$ \\
\hline FITC-albumin & & $\begin{array}{c}10 \mathrm{mg} / \mathrm{min}^{1}(65) \\
28 \text { to } 56 \mathrm{mg} / \mathrm{kg}^{2}(66)\end{array}$ & $\begin{array}{l}\text { Fluorescence (excitation } \\
\lambda_{\max } 495 \mathrm{~nm} \text {, emission } \\
\lambda_{\max } 525 \mathrm{~nm} \text { ) } \\
\text { Immunohistochemistry }\end{array}$ \\
\hline FITC-dextran & \multirow{2}{*}{$\begin{array}{l}\text { Variable, } \\
70,000 \\
\text { typically } \\
\text { used }\end{array}$} & $\begin{array}{c}5 \text { to } 750 \mathrm{mg} / \mathrm{kg}^{2}(63, \\
67,68)\end{array}$ & $\begin{array}{l}\text { Fluorescence (excitation } \\
\lambda_{\max } 492 \mathrm{~nm} \text {, emission } \\
\left.\lambda_{\max } 518 \mathrm{~nm}\right)\end{array}$ \\
\hline${ }^{3} \mathrm{H}$ - or ${ }^{14} \mathrm{C}$-dextran & & $\begin{array}{c}{ }^{3} \mathrm{H} 1 \text { or }{ }^{14} \mathrm{C} 0.5 \\
\mu \mathrm{Ci} / \mathrm{ml}^{1} \\
{ }^{3} \mathrm{H} 30 \mu \mathrm{Ci}^{2}(56) \\
{ }^{14} \mathrm{C} 4 \mu \mathrm{Ci}^{2}(53)\end{array}$ & Radiation counting \\
\hline Alexa488-labeled IgG & \multirow[t]{3}{*}{155,000} & $10 \mathrm{mg} / \mathrm{kg}^{2}(69)$ & $\begin{array}{l}\text { Fluorescence (excitation } \\
\lambda_{\max } 490 \mathrm{~nm} \text {, emission } \\
\left.\lambda_{\max } 525 \mathrm{~nm}\right)\end{array}$ \\
\hline biotinylated IgG & & $28 \mathrm{mg} / \mathrm{kg}^{2}(66)$ & Immunohistochemistry \\
\hline $\lg G$ & & Endogenous in blood & Immunohistochemistry \\
\hline
\end{tabular}

